\title{
A influência da dieta hiperproteica no auxílio da perda de gordura corpórea
}

\author{
The influence of a high-protein diet in aiding body fat loss \\ La influencia de una dieta alta en proteínas para ayudar a perder grasa corporal
}

Recebido: 23/08/2021 | Revisado: 29/08/2021 | Aceito: 30/08/2021 | Publicado: 01/09/2021

Eulina Maria Noleto da Silva

ORCID: https://orcid.org/0000-0002-3301-6821

Centro Universitário Fametro, Brasil

E-mail: eulinamariah24@gmail.com

Raylenne Mendonça de Oliveira

ORCID: https://orcid.org/0000-0002-4678-1944

Centro Universitário Fametro, Brasil

E-mail: raylennemendonca@hotmail.com

José Carlos de Sales Ferreira

ORCID: https://orcid.org/0000-0002-1867-8229

Centro Universitário Fametro, Brasil

E-mail: jcarlos.sales@gmail.com

\begin{abstract}
Resumo
Introdução: As intervenções dietéticas hiperproteicas, principalmente em pessoas obesas e sobrepeso, favorecem uma grande perda de gordura corpórea e ainda preservam a massa magra. Objetivo Geral: elucidar o mecanismo de ação das dietas hiperproteicas na redução de gordura corporal. Metodologia: Para a realização desse estudo optou-se por uma pesquisa na modalidade derevisão integrativa de literatura. A revisão integrativa determina o conhecimento atual sobre uma temática específica, já que é conduzida de modo a identificar, analisar e sintetizar resultados de estudos independentes sobre o mesmo assunto. Resultado e Discussão: Para a realização desse estudo optou-se por uma pesquisa na modalidade de revisão integrativa de literatura. A revisão integrativa determina o conhecimento atual sobre uma temática específica, já que é conduzida de modo a identificar, analisar e sintetizar resultados de estudos independentes sobre o mesmo assunto. Conclusão: Através do desenvolvimento desse estudo, foi possível demonstrar através da literatura, os benefícios de uma dieta hiperproteica, seu auxílio na redução de gordura e peso corporal.
\end{abstract}

Palavras-chave: Gordura corpórea; Excesso de peso; Dietas à base de proteína; Dieta hiperproteica.

\begin{abstract}
Introduction: Hyperprotein dietary interventions, especially in obese and overweight people, favor a great loss of body fat and still preserve lean mass. General Objective: to elucidate the mechanism of action of high-protein diets in reducing body fat. Methodology: To carry out this study, we opted for research in the form of an integrative literature review. The integrative review determines current knowledge on a specific topic, as it is conducted in order to identify, analyze and synthesize results of independent studies on the same subject. Results and Discussion: To carry out this study we opted for a research in the modality of integrative literature review. The integrative review determines currentknowledge on a specific topic, as it is conducted in order to identify, analyze and synthesize results of independent studies on the same subject. Conclusion: Through the development of this study, it was possible to demonstrate through the literature, the benefits of a high-protein diet, its help in reducing fatand body weight.
\end{abstract}

Keywords: Body fat; Overweight; Protein-based diets; High protein diet.

\section{Resumen}

Introducción: Las intervenciones dietéticas hiperproteicas, especialmente en personas obesas y con sobrepeso, favorecen una gran pérdida de grasa corporal y aún conservan la masa magra. Objetivo general: dilucidar el mecanismo de acción de las dietas ricas en proteínas en la reducción de la grasa corporal. Metodología: Para la realización de este estudio se optó por una investigación en la modalidad de revisión integradora de la literatura. La revisión integradora determina el conocimiento actual sobre un tema específico, ya que se realiza con el fin de identificar, analizar y sintetizar resultados de estudios independientes sobre el mismo tema. Resultados y Discusión: Para la realización de este estudio se optó por una investigación en la modalidad de revisión integradora de la literatura. La revisión integradora determina el conocimiento actual sobre un tema específico, ya que se realiza con el fin de identificar, analizar y sintetizar resultados de estudios independientes sobre el mismo tema. Conclusión: A través del desarrollo de este estudio, fue posible demostrar a través de la literatura, los beneficios de una dieta alta en proteínas, su ayuda en la reducción de grasas y peso corporal.

Palabras clave: Grasa corporal; Sobrepeso; Dietas a base de proteínas; Dieta rica en proteínas. 


\section{Introdução}

A obesidade é uma doença advinda de diversos fatores, podendo ser estes genéticos, psicológicos e nutricionais. Sendo caracterizada pelo excesso de gordura no tecido adiposo, onde o mesmo se dá pela ingestão excessiva de calorias com gastoenergético inferior (Floriano, et al. 2016).

Conforme dados do IBGE a obesidade entre pessoas com idade superior a 20anos aumentou de 12,2\% para 26,8\% de 2002 para 2019. Sendo, no mesmo período, o contingente de pessoas adultas que estavam acima do peso subiu de 43,3\% para $61,7 \%$. Demonstrando, assim, que o sobrepeso e a obesidade vêm aumentando dentre população brasileira (IBGE, 2019).

A alteração da dieta é um dos primeiros passos para o controle do peso e obesidade, sendo um processo longo e trabalhoso. Entretanto, é importante salientar que essa dieta deve ser adequada de acordo com a necessidade de cada indivíduo (Matteo-Galego, et al. 2017).

Nesse seguimento, na atualidade muito se tem procurado acerca de dietas com o alto teor em proteínas, principalmente entre os praticantes de atividade física tanto para o ganho de massa muscular, quanto para a perda de peso corporal (Severo, et al. 2018).

De acordo com Lorenzeti (2016), as proteínas são nutrientes essenciais que determinam ações biológicas e fisiológicas imprescindíveis para o bom funcionamentodo organismo. De acordo com Kleiner (2016), as dietas hiperproteicas, principalmente as com baixo teor de gordura, promovem uma maior perda de peso, se comparada com os outros macronutrientes como lipídeos e carboidratos.

É citado ainda pelo autor que as proteínas possuem um maior efeito desaciedade que está associada ao seu efeito termogênico, proporcionando um maiortempo de uma refeição para a outra, obtendo controle sobre o que irá ser ingeridoposteriormente e concomitantemente o controle do o peso corporal (Kleiner, 2016).

Foi constatado por Peccin (2020), que num período de 12 semanas, as dietas com o maior teor de proteínas $0,8 \mathrm{~g} / \mathrm{kg} /$ dia ocasionaram uma maior perda de gordura corporal, menor redução de massa magra e taxa metabólica basal mais elevada do que as dietas normoproteicas.

Sendo assim, as intervenções dietéticas hiperproteicas, principalmente em pessoas obesas e sobrepeso, favorecem uma grande perda de gordura corpórea e ainda preservam a massa magra. De acordo com Matteo-Galego, et al. (2017), os macronutrientes vão se diferir de acordo com seu efeito e reação no organismo, sendoa proteína o macronutriente que oferece um maior efeito de saciedade no indivíduo.

Desta forma, o desenvolvimento deste estudo justifica-se a partir do entendimento sobre a utilização de dietas à base de proteínas faz-se necessário paraque os profissionais de nutrição tenham maior segurança quanto à prescrição ou condutas alimentares. Sendo assim, o presente trabalho, tem por finalidade elucidar o mecanismo de ação das dietas hiperproteicas na redução de gordura corporal.

\section{Metodologia}

Para a realização desse estudo optou-se por uma pesquisa na modalidade derevisão integrativa de literatura. A revisão integrativa determina o conhecimento atual sobre uma temática específica, já que é conduzida de modo a identificar, analisar e sintetizar resultados de estudos independentes sobre o mesmo assunto (Silveira et al., 2008).

A Revisão Integrativa é um método de pesquisa apontado como ferramenta degrande relevância no campo da saúde, por proporcionar a busca, a avaliação crítica ea síntese de evidências sobre um tema investigado. Esses aspectos facilitam a identificação dos resultados relevantes, de lacunas que direcionam para o desenvolvimento de futuras pesquisas e auxiliam o profissional a escolher condutas ea tomar decisões, proporcionando um saber crítico (Souza, Silva \& Carvalho, 2010). 
Para extrair os dados dos artigos selecionados, será necessária a utilização deum instrumento previamente elaborado capaz de assegurar que a totalidade dos dados relevantes seja extraída, minimizar o risco de erros na transcrição, garantir precisão na checagem das informações e servir como registro (Souza, Silva \& Carvalho, 2010).

A coleta das informações para a pesquisa bibliográfica será por meio da exploração da base de dados da Biblioteca Virtual em Saúde (BVS), Biblioteca Cientifica Eletrônica Virtual (SCIELO) e Literatura Latino - Americana e do Caribe em Ciências da Saúde (LILACS).

A busca na base de dados será orientada pelos descritores: Gordura corpórea; Excesso de peso; Dietas à base de proteína; Dieta hiperproteica, e será realizado emtodos os índices, buscando captar o maior número de artigos publicados no período proposto que abordem a temática em discussão.

Para uma análise crítica e reflexiva dos estudos incluídos na revisão, será realizada uma leitura minuciosa e criteriosa destacando os que atingirem os critérios de inclusão e que contemplarem o objetivo proposto, para viabilizar o resultado da pesquisa de forma clara e objetiva.

Serão incluídos os artigos publicados em língua portuguesa nos últimos cinco anos, com texto completo, disponível on-line, com acesso livre. Serão excluídos da amostra os artigos publicados em línguas estrangeiras, os que não apresentarem o texto na integra, artigos que não apresentavam relação direta com o tema, resumos, monografias, dissertações, teses e artigos repetidos.

\section{Resultados e Discussão}

\subsection{Excesso de peso e gordura corpórea}

A Massa corporal geralmente é descrita em termos de sua composição, sendo assim, diferentes modelos foram identificados para estimar a gordura corporal, sendo o corpo dividido em massa gorda (MG) que inclui cérebro, esqueleto e tecido adiposo,e massa livre de gordura (MLG) que inclui água, proteína e componentes minerais (Mahan, 2018).

De acordo com Mahan (2018), é existente a combinação de dois tipos de gordura que se configura a gordura total do corpo, sendo a gordura essencial, necessária para o funcionamento fisiológico normal do organismo, e a gordura de armazenamento que é a reserva de energia, principalmente na forma de triglicerídeose tecido adiposo.

De acordo com Mancini (2016), existem evidências consistentes de que o excesso de peso está associado à elevação do risco de morte, sendo classificados pelo índice de massa corpórea (IMC), sendo de 25,0 a 29,9 considerado sobrepeso, de 30,0 a 34,9 considerado obesidade grau I, de 35,0 a 39,9 considerado obesidade grau II e acima de 40,0 considerado obesidade grau III, interferindo nesse quesito o risco de comorbidades.

Nesse sentido, a obesidade vem sendo considerada uma grande epidemia mundial, de incumbência da sociedade e do poder público, por estar associada a considerável morbimortalidade, e definida como doença crônica associada ao excesso de gordura corporal (acúmulo de tecido adiposo localizado ou generalizado), com etiologia complexa e multifatorial, resultando da interação de estilo de vida, genes e fatores emocionais (Mancini, 2016).

De acordo com Severo (2018), o processo de transição demográfica e epidemiológica e o aumento da prevalência de doenças crônicas não transmissíveis trazem consigo implicações no estado nutricional e na composição corporal da população.

Em concordância a isso é citado por Mancini (2016) que uma grande preocupação médica é o risco elevado de doenças associadas ao sobrepeso e à obesidade, tais como diabetes, doenças cardiovasculares (DCV) e alguns tipos de câncer, por isso é crucial a identificação dessas comorbidades e os resultadosadversos.

Conforme a literatura estudada, a obesidade é multifatorial, sendo considerados tais fatores: genético, nutricional, inatividade, endócrino, hipotâmico e drogas (Verreijen, et al. 2017). 
De acordo com Mahan (2018), o tecido adiposo além de ter a função de estoque de energia, também são células biologicamente ativas que trabalham no mecanismo de inflamação subclínica. Que por sua vez formam um conjunto de alteraçõesbioquímicas, fisiológicas e imunológicas.

Sendo assim, nota-se que a obesidade é casualmente associada à incapacidade funcional e qualidade de vida reduzida, doença grave, redução da expectativa de vida e maior mortalidade (Mancini, 2016).

Para a obtenção de um tratamento ou prevenção da obesidade, se faz necessário um controle entre o gasto energético e o seu consumo, atrelando uma atividade física a uma dieta balanceada, assim aumentando o gasto energético e diminuindo o consumo calórico (Verreijen, et al. 2017).

\subsection{A proteína no organismo e sua digestibilidade}

O termo "proteína" foi criado pelo químico sueco Jons Jakob Berzerlius (1779-1848) e, posteriormente, aceito e promovido pelo influente químico holandês Gerhardus Mulder, em 1838. Sendo sua relevância na dieta reconhecida por Magendie em 1816, após estudos realizados com cães, determinado uma fonte de nitrogênio essencial na alimentação (Mcardle, 2016).

As proteínas são as mais abundantes macromoléculas biológicas e representam o principal componente estrutural e funcional de todas as células do organismo (Peccin, 2016). Em sua complexidade, as proteínas possuem diversas conformações possíveis, suas funções biológicas se ampliam desde o estoque,proteção, regulação e transporte.

De acordo com McArdle (2016), um adulto possui em média de 10 a $12 \mathrm{~kg}$ de proteína detectado principalmente dentro da massa dos músculos esqueléticos.Responsáveis pelas funções de transporte, estrutural, presente em diversos tecidos, enzimática, hormonal, de defesa (anticorpos), dentre outros. As proteínas dispõem de uma grande capacidade de constituição estrutural para o desenvolvimento e funcionamento do tecido muscular.

Acordante com Peccin (2016), as carências nutricionais de aminoácidos no serhumano são atendidas pela absorção de aminoácidos e pequenos peptídeos oriundosde proteínas da dieta e sua digestão. É sabido que o organismo não faz estocagem de proteínas ou aminoácidos, sendo necessário seu aporte diário através da dieta.

Nesse sentido as proteínas são demasiado complexas para serem absorvidas pelo intestino. Como tal, devem ser hidrolisadas para originar os seus aminoácidos constituintes, os quais podem ser absorvidos (Cabrita, 2017).

Conforme Lorenzeti (2016), depois de ingeridos os aminoácidos são usufruídospara formação de proteínas estruturais, hormônios, neurotransmissores e enzimas ou são metabolizados, conseguindo operar como precursores ou intermediários do ciclode Krebs, uma parte sendo eliminada no ciclo da ureia.

As proteínas ingeridas na dieta estão envolvidas no metabolismo do nitrogêniopor meio do pool de aminoácidos no organismo. Consistindo na taxa de renovação proteica, qual o organismo exerce síntese de ATP e síntese de corpos cetônicos, ácidos graxos e esteroides (Matteo-Galego, et al. 2017).

Sua ingestão na dieta é através das proteínas, que irão interferir de acordo coma quantidade ingerida, sendo um indivíduo adulto tendo que consumir em média 6,25g de proteínas para $1 \mathrm{~g}$ de nitrogênio, seu equilíbrio se dá conforme sua ingestão e excreção respectivamente (Perroni, 2016).

Acordante com Lorenzeti (2016), as proteínas iniciam sua digestão no estomago, ocorrendo o aumento da pepsina, liberando ácido clorídrico, em consequência diminuindo o pH do estomago. Ocasionado a ativação da pepsina, neutralização de organismos patogênicos, aumento da absorção de ferro e cálcio, inativação de hormônios de origem animal e vegetal, desnaturação das proteínas ingeridas e facilitação da ação enzimática. 


\subsection{A Dieta Hiper proteica Versus a Redução de Gordura Corporal}

Elementos estruturais e funcionais, as proteínas são macronutrientes essências para o organismo, formadas por carbono, hidrogênio, oxigênio e nitrogênio, em conjunto com fósforo, ferro, cobalto e outros minerais. Auxiliando diversas interações metabólicas substanciais se faz presente em grande parte no organismo humano (Amancio, et al. 2016).

Dietas à base de proteínas, para a perda de peso, se tornaram moda em todo o mundo, sendo a do Dr. Atkins a mais famosa, que anula o consumo de carboidratos permitindo apenas o consumo de proteínas e gorduras (Matteo-Galego, et al. 2017).

Sendo a dieta hiperproteica definida como aquela que excede os limites diários do recomendado, sendo este, 0,8 $\mathrm{g} / \mathrm{kg}$ para indivíduos saudáveis. É citado por Verreijen, et al. (2017), que a dieta hiperproteica é definida como aquela que fornecede 1,8 a 3,3 $\mathrm{g} / \mathrm{kg}$ peso dia de proteínas.

De acordo com Floriano, et al. (2016), o aumento do consumo de proteínas pode tanto favorecer a perda de massa corporal como propiciar sua manutenção, poisa proteína proporciona um efeito de maior saciedade, podendo estar atrelado às alterações fisiológicas resultantes de sua ingestão.

Com isso, as dietas hiperproteicas são eficientes, pois o organismo trabalha muito para extrair as suas calorias, sendo $30 \%$ de seu consumo utilizado para essa extração calórica (Amancio, et al. 2016).

De acordo com Silva, Santana (2019), essas necessidades aumentam com o tipo de exercício praticado, sua intensidade, duração e frequência, pois dietashiperproteicas aumentam o volume muscular, força e melhoram desempenho. Aindaconforme o referido autor, a ingestão diária de proteínas varia de $0,8 \mathrm{~g} / \mathrm{kg}$ a $1,8 \mathrm{~g} / \mathrm{kgdia}$, abrangendo as necessidades de pessoas sedentárias a atletas, respectivamente. A concentração e a disponibilidade dos aminoácidos dos indispensáveis individuais consistem fatores importantes, responsáveis pelas diferenças nos valores nutritivos das proteínas dos alimentos. Sendo as fontes proteicas de alto valorbiológico provenientes de fonte animal, enquanto as de fonte vegetal sendo consideradas de baixo valor biológico (Mcardle, 2016).

De acordo com Kleiner (2016), para o aumento do uso da proteína na dieta é fundamental pesar algumas fontes adicionais, carnes magras, peixes e aves, mas também os laticínios semidesnatados e derivados de soja.

A qualidade de uma fonte proteica é determinada pelo perfil e biodisponibilidade dos aminoácidos essenciais e pela digestibilidade do alimento. Ainda de acordo com o referido autor, as melhores fontes de proteínas com o alto valor biológico são, respectivamente, as de fonte animal (carne, peixe, ovos e laticínios), as de fonte vegetal (leguminosas, cereais, frutas secas), e os suplementos (whey, caseína,proteína de soja e proteína de arroz) (Cabrita, 2017).

Conforme alguns estudos, dietas ricas em proteínas e pobres em gordura proporcionam uma grande perda de peso, isso porque a proteína magra auxilia na queima de gordura, pois possuem efeito termogênico (Kleiner, 2016).

De acordo com Cabrita (2017), todos os alimentos tem a capacidade de aumentar a temperatura corporal, pois precisam de energia para serem digeridos, no entanto isso poderá variar de acordo com a sua composição. Os alimentos com efeitotermogênico demandam uma maior energia do organismo para serem digeridos.

Acordante com Floriano, et al. (2016), a adesão de dietas hiperproteicas e hipocalóricas auxiliam na preservação de massa magra e perda ponderal de gordura corpórea, melhorando a sensibilidade insulínica primordialmente em indivíduos obesos.

As dietas hiperproteicas privilegiam o consumo de proteínas e gorduras em relação ao de carboidratos. Ingerir mais proteínas diminui o apetite ao aumentar a produção de hormônios que ajudam a pessoa a se sentir saciada. Também aumenta a taxa metabólica e traz efeitos benéficos à composição corporal, diminuindo o peso corporal (Floriano, et al. 2016)

Como a proteína participa da formação de músculos e ossos, a dieta hiperproteica pode ajudar a ganhar massa muscular e a reduzir a perda dela duranteo envelhecimento, chamada de sarcopenia. O consumo do macronutriente também é 
fundamental no envelhecimento para assegurar a boa saúde dos ossos. Além disso, dietas hiperproteicas já foram associadas à redução da pressão sanguínea e dos níveis de colesterol e triglicérides (Mérida, et al. 2018).

\section{Conclusão}

Através do desenvolvimento desse estudo, foi possível demonstrar através da literatura, os benefícios de uma dieta hiperproteica, seu auxílio na redução de gordurae peso corporal. De maneira a contribuir tanto para o conhecimento geral das pessoasque buscam por dietas contemporâneas, quanto para os profissionais da área da saúde e nutrição que necessitem de embasamento nesse contexto.

Nesse seguimento, tem-se em vista que a dieta hiperproteica é uma boa estratégia para o processo de emagrecimento, todavia a quantidade de cada macronutriente na dieta deve ser ajustada de acordo com cada indivíduo. Ressalta-se a importância do nutricionista para tal acompanhamento.

\section{Referências}

Almeida, Jussara C. de. Rodrigues, Ticiana C., Silva, Flávia M., \& Azevedo, Mirela J. de. (2009). Revisão sistemática de dietas de emagrecimento: papel dos componentes dietéticos. Revisão sistemática de dietas de emagrecimento: papel dos componentes dietéticos. Arq Bras Endocrinol Metab 53(5) https://www.scielo.br/j/abem/a/rkpFTjXYdMrNFMz3q7W8FTf/?lang=pt • https://doi.org/10.1590/S0004-27302009000500020 “.

Amancio, L. C. F., Franco, J. R., Alves, H. C. C., \& Carmo, J. F. V. do. (2016). Dietas hiperproteicas: a busca por um corpo esbelto e ou hipertrofiado. Faculdade Atenas.

Baptista, T. J. R. (2013). A obesidade e a indústria do emagrecimento. Rev. ComCiência. (145), 1-4. http://comciencia.scielo.br/scielo.php?script=sci_arttext\&pid=S1519-76542013000100009\&lng=pt\&nrm=iso. ISSN 1519-7654.

Beck, K. L., Thomson, J. S., Swift, R. J., \& Hurst, P.R.V. (2016). Role of nutrition in performance enhancementandpostexerciserecovery. Open Acess Journal of Sports Medicine. New Zealand. 11(3), 269-267.

Cabrita, André Felipe Oliveira. (2017). Dietas hiperproteicas: metabolismo, efeitos, segurança e suplementação. Dissertação (Grau de Mestre em Medicina) Universidade da Beira interior, ciências da saúde, Covilhão.

Campos-Nonato, I., Hernandez, L., \& Barquera, S. (2017). Effectof a High-Protein Diet versus Standard Protein Diet on Weight Loss and Biomarker sof Metabolic Syndrome: A Randomized Clinical Trial. Obesity Facts. 10, 238-251.

Dantas, Estélio H. M. (2016). Obesidade e emagrecimento. Shape.

Esteves, E. A., Ávila, M. V. P., \& Almeida, F. Z. (2017). Ingestão calórica e relações entre ingestão proteica e variáveis de adiposidade em mulheres adultas.

Faria, L. N., Souza, A. A. de. (2017). Análise nutricional quantitativa de uma dieta da proteína destinada a todos os públicos.

Floriano, R. S., Mazur, C. E., Schwarz, K., Benincá, S. C., \& Machado, T. W. M. (2016). Dietas para emagrecimento publicadas em um magazine direcionado ao público feminino: análise do conteúdo nutricional. Scientia Médica. 26(2), 1-8.

Gibson, A. A., et al. (2016). Fast versus slow weight loss: development processand rationale behind the dietary intervations for TEMPO Diet Trial. Obesity Science \& Practice. 2(2), 162-173.

Gomes, R.V., Ribeiro, S. M. L., Veibig, R. F., \& Aoki, M. S. Consumo alimentar e perfil antropométrico de tenistas amadores e profissionais. Revista Brasileira de Medicina do Esporte. 15(6.2009), 43-440.

Helms, E. R. et al. (2016). Evidence-based recommendations for natural body Building contest preparation: nutrition and supplementation, Journal of the International Society of Sports Nutrition, 11(20).

IBGE- Instituto brasileiro de geografia e estatistica. Um em cada quatro adultos do país estava obeso em 2019; atenção primária foi bem avaliada.

Johnston C. S., Day C. S., \& Swan P. D. (2016). Post prandial thermogenesisis increased 100\% on a high-protein, low-fat diet versus a high-carbo hydrate, low-fat diet in healthy, Young women. J Am Coll Nutr, 21(1), 55-61.

Johnston C. S., Tjonn S. L., Swan P. D. (2004). High-protein, low-fat diets are effective for weight loss and favorably alter biomarkers in healthy adults. $J$ Nutr. 134(3):586-91.

Johnstone A. M., Horgan G. W., \& Murison S. D., et al. (2018). Effects of a high-protein ketogenic diet on hunger, appetite, and weightloss in obesemen feeding ad libitum. Am J ClinNutr, 87(1), 44-55.

Joo N.S., Park Y. W., Park K. H., et al. (2018). Application of protein-rich oriental diet in a community-based obesity control program. Yonsei Med J, 52(2), 249-256. 
Kac G., Benício M.H., Velásquez-Meléndez G., et al. (2016). Gestation al weight gainand prepregnancy weight influence post part um weight retention in a cohort of Brazilian women. J Nutr, 134(3), 661-666.

Kleiner, Susan M., et al. (2016). Nutrição para o treinamento de força. [tradução Leda Pierrotti]. (4a ed.), Manole.

Larosa, Glauce. (2016). Dieta hiperprotéica.

Li Z., Treyzon L., Chen S. et al. (2016). Protein-enriched meal replacements do not adverse lya ffectliver, kidne yorbon edensity: anout patient randomized control led trial. Nutr J, 9(72), 1-7.

Lida T., Kishimoto Y., Yoshikawa Y., et al. (2018). Acute d-psicose administration decreases the glycemic responses toan oral malto dextrin tolerancet est in normal adults. $J$ NutrScvitam, 54(6), 511-514.

Lima, E. dos S., Ribeiro, D. G., Jesus, E. B. A. de, Feitosa, M. A. de S., Silva, Y. G. C., \& Neto, A. C. de O. (2021). Alimentos termogênicos no controle da obesidade.

Liu B., Balkwill A., Reeves G., et al. (2016). Body mass index andrisk of liver cirrhosis in Middle aged UK women: prospective study. BMJ, $340(912)$, 1-7.

Lorenzeti, Fábio Medici. (2016). Nutrição e suplementação esportiva: aspectos metabólicos, fitoterápicos e da nutrigenômica. Phorte.

Mahan, L. Kathleen. (2018). Krause alimentos, nutrição e dietoterapia/ L. Kathleen Mahan, Janice L. Raymond; [tradução Verônica Mannarino, Andréa Favano]. (14a ed.), Elsevier.

Mancini, Marcio C., et al. (2016). Tratado de obesidade. (2a ed.), Guanabara Koogan.

Matteo-Galego, R., Marco-Benedí, V., Perez-Calahorra, S., Bea, A. M., Baila-Rueda, L., Lamiquiz-Moneo, I., Castro-Orós, I., Cenarro, A., \& Civeira, F. (2017). Energy-restricted high protein diets more effective lyimpact cardiometalic profile in over weight and obese women than lower-protein diets. Clinical Nutrition, 36, 371-379.

Mcardle, William D., et al. (2016). Nutrição para o esporte e o exercício; [traduzido por Giuseppe Taranto]. Guanabara Koogn.

Mérida, D., Anunciata, L., Silva, G., Cristina, D., Toffolo, F., \& Cardoso, M. (2018). Prevalência de excesso de peso em funcionários de uma instituição privada de ensino. Nutr.clín.diet.hosp, 38(1). .27-31.

Michael, J. Gibney, et al. (2016). Introdução à nutrição humana/ editado, em nome da Nutrition Society [tradução Patricia Lydie Voeux; revisão técnica Miguel CralosRiella]. (2a ed.), Guanabara Koogan.

Miranda, V. P. N., Peluzio, M. Do C. G., Franceschini, S. Do C. C., \& Priore, S. E. (2016). Marcadores inflamatórios na avaliação nutricional: relação com parâmetros antropométricos, composição corporal e níveis de atividade física. Rasbran- Revista da associação brasileira de nutrição.

Moreira, F. P., \& Rodrigues, K. L. (2014). Conhecimento nutricional e suplementação alimentar por praticantes de exercícios físicos. Revista Brasileira de Medicina do Esporte. São Paulo, 20(5), 370-73.

Paschoal, V. (2017). Tratado de nutrição esportiva funcional/ Valéria Paschoal, Andréia Naves. Roca.

Peccin, S. (2016). É possível evitar a recuperação do peso após o emagrecimento? Acta médica, 35(2), 247-258.

Pedrosa, R. G., Junior, J. D., \& Tirapegui, J.(2019). Dieta rica em proteína na redução de peso corporal.

Perroni, Cristiane. (2016). Dieta da proteína acelera perda de peso e redução de gordura corporal.

Quintão D. F., Oliveira, G. C., Silva, S.A., \& Marins, J. C. B. (2015). Estado nutricional e perfil alimentar de atletas de futsal de diferentes cidades do interior de Minas Gerais. Revista Brasileira de Futebol. 2(1), 13-20.

Rajaie, S. et al. (2016). Moderate replacement of carbo hydrates by dietary fat saffects features of metabolics yn drome: A randomized crossover clinical trial, Nutrition, 30, 61-68.

Rossi, L., Tirapegui, J., \& Castro, Inar Alves de. (2016). Restrição moderada de energia e dieta hiperproteica promovem redução ponderal em atletas de elite do karatê.

Santos, A. L. A. (2017). Dieta hiperproteica e sua influência no gasto energético, perda de peso, composição corporal e marcadores metabólicos em homens obesos.

Severo, P. R. F., Borges, V. S., Moraes, M. F. L., Magalhães, G. A., Lemos, E. J., \& David, L. M. M. (2018). Dieta hiperproteica e função renal: Discutindo seus efeitos em adultos normais. Acta médica, 39(1), 247-258.

Silva, G. dos S., \& Santana, Y. C. de. (2019). Influência da dieta hiperproteica associada a atividade física no emagrecimento: Revisão sistemática.

Silva, S. M. C. S. da, et al. (2016). Tratado de alimentação, nutrição e dietoterapia (2a ed.), Roca.

Souza, M. T., Silva, M. D., \& Carvalho, R. (2010). Revisão integrativa: o que é e como 15 fazer. Einstein, 8(1), $102-106$.

Theodoro, H., Ricalde, S. R., \& Amaro, F. S. (2009). Avaliação nutricional e autopercepção corporal de praticantes de musculação em academias de Caxias do Sul-RS. Revista Brasileira de Medicina do Esporte, 15(4), 291-294. 
Research, Society and Development, v. 10, n. 11, e295101119722, 2021

(CC BY 4.0) | ISSN 2525-3409 | DOI: http://dx.doi.org/10.33448/rsd-v10i11.19722

Verreijen, A. M., Engberink, M. F., Mamelink, R. G., Van Der Plas, S. E., Visser, M., \& Weijs, P. J. M. (2017). Effectof a high protein diet and or resistance exercise on the preservation of fat free mass during weight loss in over weight and obese old eradults: a randomized controlled trial. Nutrition Journal, 16(10), $1-8$.

Wycherley T. P., Brinkworth G. D., Clifton P. M. et al. (2015). Comparis on of the effects of 52 week sweight loss withei ther a high-proteinor highcarbohydrate diet on body composition and cardiometabolic risk factors in over weight and obese males. Nutr Diabetes, 2(8), 1-8.

Wycherley T. P., Moran L. J., Clifton P. M. et al. (2016). Effects of energy-restricted high protein, low-fat compared with standard-protein, low-fat diets: a meta-analys is of randomized control led trials. Am J Clin Nutr, 96(6), 1281-1298.

York L. W., Puthalapattu S., \& Wu G. Y. (2015). Non alcocholic fat tyliver disse aseand lowcarbohydrate diets. Annu Rev Nutr, 29(1), 365-379. 